\title{
REVIEW
}

\section{Clinical review: Oxygen as a signaling molecule}

\author{
Raquel R Bartz',2* and Claude A Piantadosi ${ }^{1,2,3}$
}

\begin{abstract}
Molecular oxygen is obviously essential for conserving energy in a form useable for aerobic life; however, its utilization comes at a cost - the production of reactive oxygen species (ROS). ROS can be highly damaging to a range of biological macromolecules, and in the past the overproduction of these short-lived molecules in a variety of disease states was thought to be exclusively toxic to cells and tissues such as the lung. Recent basic research, however, has indicated that ROS production - in particular, the production of hydrogen peroxide - plays an important role in both intracellular and extracellular signal transduction that involves diverse functions from vascular health to host defense. The present review summarizes oxygen's capacity, acting through its reactive intermediates, to recruit the enzymatic antioxidant defenses, to stimulate cell repair processes, and to mitigate cellular damage.
\end{abstract}

\section{Oxygen as a biological molecule}

Oxygen $\left(\mathrm{O}_{2}\right)$ is perhaps the single most important molecule for the maintenance of life on Earth. The geological record indicates that our planet's atmospheric $\mathrm{O}_{2}$ concentration has fluctuated substantially, and this is thought to be involved in the evolution of a broad array of antioxidant defenses. This important and reactive molecule first appeared in our atmosphere over 2.2 billion years ago, and millions of years ago may have been as high as $35 \%$ of the atmospheric composition. Not until atmospheric $\mathrm{O}_{2}$ levels had stabilized at around 21\% more than 500 million years ago and intracellular mechanisms evolved to utilize $\mathrm{O}_{2}$ efficiently and to contain its reactivity, however, did complex multicellular organisms began to proliferate.

Because $\mathrm{O}_{2}$ has a high standard oxidation-reduction (redox) potential, it is an ideal electron acceptor - and is

*Correspondence: bartz001@mc.duke.edu

'Department of Anesthesiology, Duke University School of Medicine, Box 3094

Durham, NC 27710, USA

Full list of author information is available at the end of the article therefore a sink for the capture of energy for intracellular use. The reactivity of $\mathrm{O}_{2}$, however, also has a cost; $\mathrm{O}_{2}$ is a strong oxidizing agent that strips electrons from biological macromolecules and induces intracellular damage. Unless adequate defenses are present to control and repair the damage induced by its reactive intermediates, $\mathrm{O}_{2}$ toxicity supervenes. This is particularly well known to the intensive care unit physician, as prolonged exposure of the human lung to more than $60 \%$ oxygen at sea level causes diffuse acute lung injury [1].

The toxicity of $\mathrm{O}_{2}$ is due to its intermediate species, known as reactive oxygen species (ROS), which are normally scavenged by multiple cellular antioxidant systems present in both prokaryotic cells and eukaryotic cells. Although $\mathrm{O}_{2}$ 's role as an intracellular electron acceptor in respiration has been understood for more than 100 years and the cell's main defense mechanisms against $\mathrm{O}_{2}$ 's toxic effects were discovered more than 50 years ago, we are currently entering a new era of understanding how $\mathrm{O}_{2}$ and ROS operate as cell signal transduction mechanisms in order to maintain intracellular homeostasis and to adapt to cell stress. The present review is focused on $\mathrm{O}_{2}$ 's capacity, acting through such reactive intermediates, to modulate signal transduction.

\section{Oxygen utilization and metabolism}

Approximately 90 to $95 \%$ of the $\mathrm{O}_{2}$ consumed by the body is utilized by mitochondria to supply cellular energy through respiration and oxidative phosphorylation [2,3]. Oxidative phosphorylation conserves energy from the breakdown of carbon substrates in the foods we ingest in the form of ATP, which is vital for cell function. To generate ATP by aerobic respiration, $\mathrm{O}_{2}$ is reduced to water in a four-electron process without the production of ROS. ATP is then hydrolyzed to ADP, providing energy to perform basic cellular functions such as the maintenance of ion gradients and the opening of ion channels for nerve conduction, for muscle contraction, and for cell growth, repair, and proliferation.

Energy in the form of ATP is derived from the oxidation of dietary carbohydrates, lipids, and proteins. The proportion of carbohydrates, lipids, and proteins utilized to produce ATP is cell specific and organ specific. For example, adult brain cells (in the fed state) and erythrocytes utilize carbohydrates, whereas the energy for 
cardiac contraction derives primarily from fatty acid oxidation [4-6]. Although $\mathrm{O}_{2}$ is necessary for aerobic ATP generation, ROS can be produced as a by-product of the nonspecific transfer of electrons to $\mathrm{O}_{2}$ by either mitochondrial electron transport proteins or by nonenzymatic extramitochondrial reactions. Moreover, numerous endogenous ROS-producing enzymes utilize molecular $\mathrm{O}_{2}$ for their reactions. The production of ROS by some normal and most pathological mechanisms increases as a function of the oxygen concentration in the tissue, which can result in both direct molecular damage and interference with essential redox regulatory events as described later. A diagram of molecular $\mathrm{O}_{2}$ use by these enzyme systems and the downstream consequences good and bad - is shown in Figure 1.

Because $\mathrm{O}_{2}$ and its intermediates are highly reactive, elegant but complex systems have evolved to allow for the continuous production of ATP while minimizing ROS production by normal metabolism. The proteins of the respiratory complexes, for instance, only allow about 1 to $2 \%$ of the $\mathrm{O}_{2}$ consumed by the mitochondrial electron transport system to generate ROS. This sequence of oxidation-reduction reactions generates a flow of electrons through Complexes I to IV of the electron transport system, which produces an electromotive force across the inner mitochondrial membrane used by the ATPase, also known as Complex V, to synthesize ATP. In the process, small quantities of singlet oxygen and superoxide anion $\left(\mathrm{O}_{2}^{-}\right)$are produced primarily at Complex I and Complex III in proportion to the local $\mathrm{O}_{2}$ concentration and the reduction state of the carrier. Although such ROS can clearly damage mitochondria and adjacent organelles by oxidizing DNA, proteins, and lipids, or by promoting the formation of adducts with DNA, mitochondria are protected by superoxide dismutase (SOD2) and their own glutathione and peroxidase systems. The small amount of $\mathrm{O}_{2}{ }^{-}$that mitochondria do produce is quickly converted to hydrogen peroxide $\left(\mathrm{H}_{2} \mathrm{O}_{2}\right)$, some of which escapes to the cytoplasm and participates in intracellular signal transduction. In fact the majority of ROS-induced cell signaling research has focused on catalytic changes induced by the oxidation of cell signaling proteins by $\mathrm{H}_{2} \mathrm{O}_{2}$, which is the main focus of the present review.

\section{Oxygen toxicity: reactive oxygen species production}

As already mentioned, $\mathrm{O}_{2}$ and its intermediate forms are highly reactive and $\mathrm{O}_{2}$ concentrations $>21 \%$ have been known for decades to be toxic to plants, animals, and bacteria [7-9]. The major ROS are produced by sequential single electron reductions of molecular $\mathrm{O}_{2}$, including $\mathrm{O}_{2}^{-}, \mathrm{H}_{2} \mathrm{O}_{2}$ and the hydroxyl radical (Figure 2). Small amounts of peroxyl, hydroperoxyl, and alkoxyl radicals are also produced - as is the peroxynitrite anion, primarily from the reaction of $\mathrm{O}_{2}{ }^{-}$with nitric oxide [10]. These reactive molecules are short-lived oxidants that react with one or more electrons on intracellular proteins, lipids, and DNA; if left unrepaired and unabated, these molecules can lead to cell death via apoptosis and/or necrosis. Moreover, the release of oxidized or cleaved macromolecules into the extracellular space may have specific and nonspecific proinflammatory effects.

The range of molecular damage produced by ROS is rather remarkable, and encompasses, for instance, lipid peroxidation and nitration, protein oxidation and protein nitration, protein-thiol depletion, nucleic acid hydroxylation and nitration, DNA strand breakage and DNA adduct formation. To prevent and repair such diverse ROS-mediated cellular damage, a range of mechanisms have evolved that are upregulated during periods of excessive ROS generation - commonly known as oxidative stress - including antioxidant and repair enzymes, and which, not surprisingly, are under the control of cellular signals generated by ROS themselves.

Although mitochondria are highly efficient at reducing $\mathrm{O}_{2}$ completely to water, they are still the greatest in vivo source of intracellular ROS production simply because of the amount of $\mathrm{O}_{2}$ consumed during oxidative phosphorylation [11,12]. Mitochondrial ROS generation, however, is increased at higher oxygen pressure levels as well as by mitochondrial damage; for instance, by mitochondrial swelling during the mitochondrial permeability transition, which uncouples oxidative phosphorylation and increases ROS production. Uncoupling does not, however, always increase ROS production; indeed, the production of ROS may actually decrease via the expression of uncoupling proteins, which may relieve the electron escape to molecular oxygen.

The extent of mitochondrial ROS generation also varies with the type of tissue and the level of damage to the mitochondria. For instance, rat heart mitochondria normally produce more $\mathrm{H}_{2} \mathrm{O}_{2}$ than liver mitochondria [13] and mitochondria of septic animals produce more $\mathrm{H}_{2} \mathrm{O}_{2}$ than mitochondria of healthy controls [14]. A key point is that the regulation of tissue oxygen pressure is a critical factor for the control of ROS production, and loss of this regulation in diseases such as sepsis increases the amount of oxidative tissue damage.

\section{Prevention of oxidative damage: balancing oxygen utilization and the antioxidant defenses}

The generation of ROS under homeostatic conditions is balanced by antioxidant defenses within and around cells, which include both enzymatic and nonenzymatic mechanisms. Antioxidant enzymes catalytically remove ROS, thereby decreasing ROS reactivity, and protect proteins through the use of protein chaperones, transition 


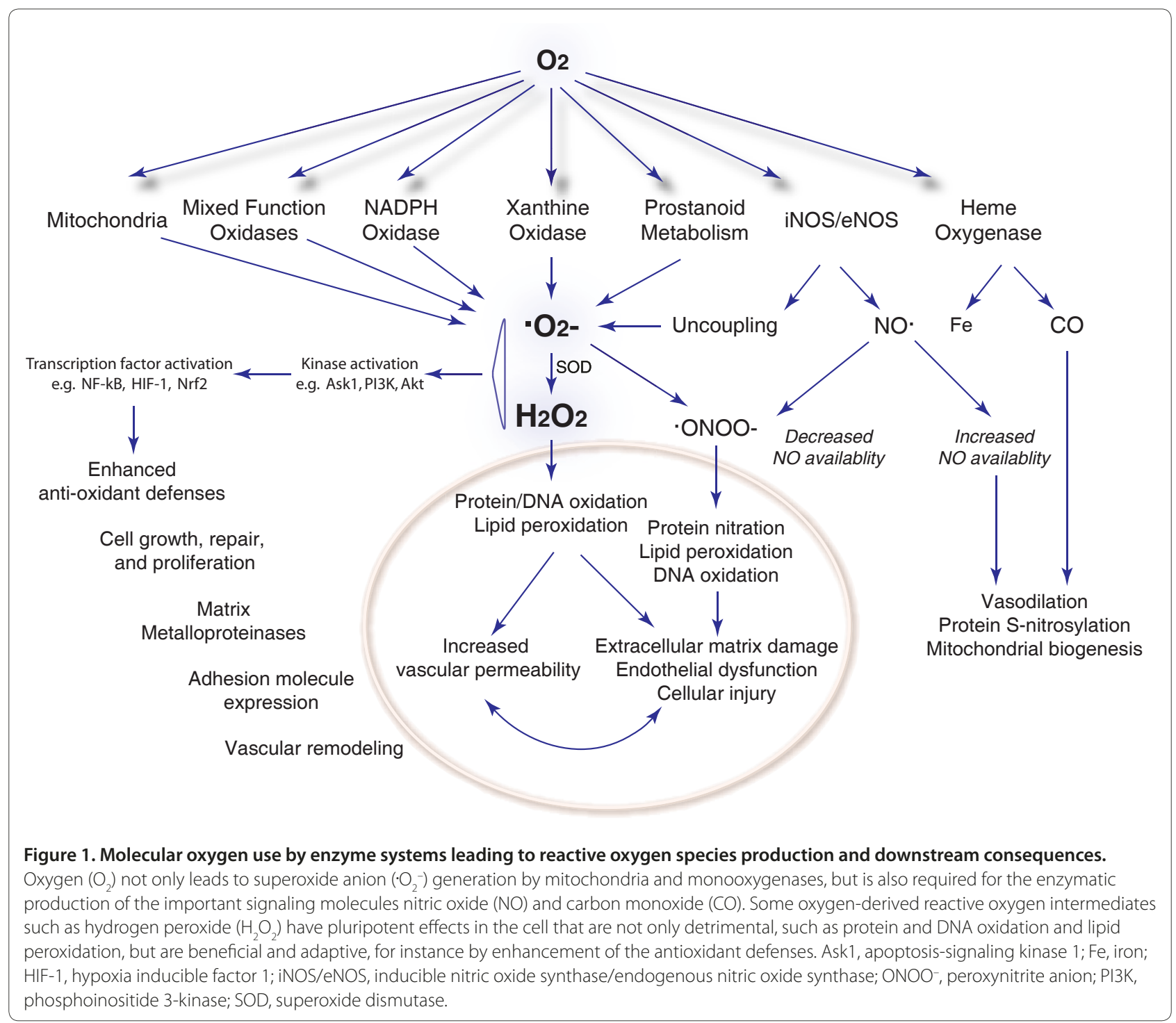

metal-containing proteins, and low-molecular-weight compounds that purposely function as oxidizing or reducing agents to maintain intracellular redox stability.

The first-line antioxidant enzymes, the SODs, are a ubiquitous group of enzymes that efficiently catalyze the dismutation of superoxide anions to $\mathrm{H}_{2} \mathrm{O}_{2}$. Three unique and highly compartmentalized mammalian superoxide dismutases have been characterized. SOD1, or CuZnSOD, was the first to be discovered - a homodimer containing copper and zinc found almost exclusively in the cytoplasm. SOD2, or Mn-SOD, is targeted by a peptide leader sequence exclusively to the mitochondrial matrix, where it forms a tetramer [15]. SOD3, or ECSOD, the most recently characterized SOD, is a synthesized copper and zinc-containing tetramer with a signal peptide that directs it exclusively to the extracellular space [16]. The presence of SOD2 helps to limit

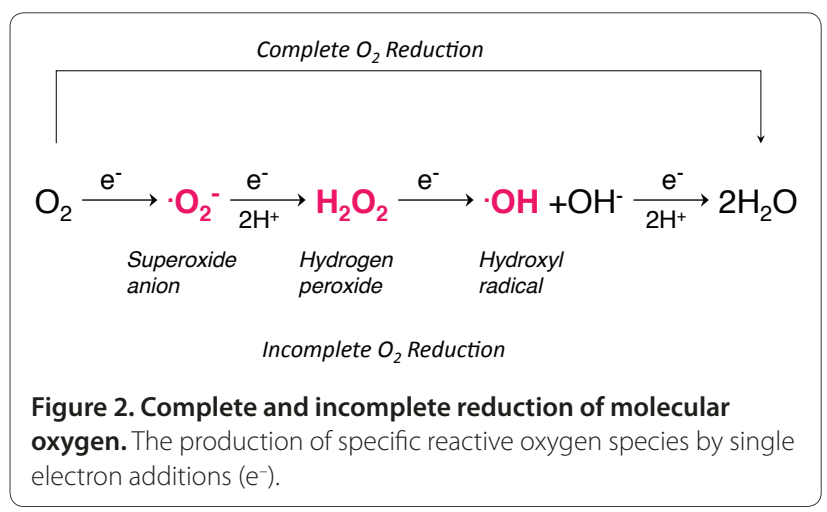

$\mathrm{O}_{2}{ }^{-}$levels and location; within the mitochondrial matrix, for instance, the enzyme's activity increases at times of cellular stress [15]. This isoform is required for cellular homeostasis, and SOD2 knockout mice die soon after 
birth and exhibit cardiac abnormalities, hepatic and skeletal muscle fat accumulation, and metabolic acidosis [17].

The product of SOD, $\mathrm{H}_{2} \mathrm{O}_{2}$ is usually degraded by peroxidases to prevent subsequent cellular damage; however, $\mathrm{H}_{2} \mathrm{O}_{2}$ may also function as a signaling molecule. Although produced in small amounts under homeostatic circumstances, $\mathrm{H}_{2} \mathrm{O}_{2}$ production may increase in response to cellular stresses such as inflammation. For cells to maintain normal $\mathrm{H}_{2} \mathrm{O}_{2}$ tone, therefore, other antioxidant defenses have evolved - including two main classes of enzymes. $\mathrm{H}_{2} \mathrm{O}_{2}$ is converted to water and $\mathrm{O}_{2}$ by catalase or to water and an oxidized donor by peroxidases, such as the selenium-containing glutathione peroxidases. Catalase is sequestered in mammalian cells within the peroxisomes, which can be clustered around the mitochondrial outer membrane $[18,19]$. Much of the $\mathrm{H}_{2} \mathrm{O}_{2}$ produced within mitochondria and diffusing past the outer membrane is therefore converted to water and $\mathrm{O}_{2}$. The glutathione peroxidase enzymes couple $\mathrm{H}_{2} \mathrm{O}_{2}$ reduction to water with the oxidation of reduced glutathione to the glutathione disulphide, which is then reduced back to reduced glutathione primarily by the activity of the pentose phosphate shunt. Glutathione peroxidase isoenzymes are widely distributed in cells and tissues, and are mostly specific for reduced glutathione as a hydrogen donor [20]. Mitochondria and certain other organelles also contain other systems to detoxify ROS, including glutaredoxin, thioredoxin, thioredoxin reductase, and the peroxiredoxins.

Other important enzymes with essential antioxidant and signaling functions are the heme oxygenases (HO-1 and $\mathrm{HO}-2$ ). HO-1 is the stress-inducible isoform, also called HSP 32, and utilizes molecular $\mathrm{O}_{2}$ and NADPH to catalyze the breakdown of potentially toxic heme to biliverdin, releasing iron and carbon monoxide. Biliverdin is converted to bilirubin in the cytosol by the enzyme biliverdin reductase. HO-1 is ubiquitous, but levels are especially high in Kupffer cells of the liver, in the lung, and in the spleen. HO-1 knockout mice have anemia and tissue iron accumulation and low plasma bilirubin.

HO-1 thus functions to remove a prooxidant (heme) and generate an antioxidant (biliverdin), and the iron and carbon monoxide have important signaling roles, especially during cell stress. The iron is initially a prooxidant mainly because ferrous iron can donate an electron to acceptor molecules - if this is $\mathrm{H}_{2} \mathrm{O}_{2}$, the hydroxyl radical is generated and causes oxidative stress. If ferric iron can be reduced, the cycle continues (for example, a superoxide-driven Fenton reaction). Ferric iron is not highly reactive, however, and many ironcontaining enzymes are inactive in the ferric state. HO-1 knockout mice are therefore susceptible to inflammation and hypoxia but may actually suffer less lung damage when exposed to $100 \% \mathrm{O}_{2}$ [21], perhaps in part due to the recruitment of iron defenses such as ferritin. HO-1 induction, however, provides protection against ischemiareperfusion injury of the heart and brain, provides protection in severe sepsis, and plays a role in tissue repair and in mitochondrial biogenesis [22-24]. Approaches to capitalize on the beneficial effects of HO-1 induction during periods of oxidative stress in critical illness is an area of active investigation.

Nonenzymatic antioxidants such as reduced glutathione, vitamin $C$, vitamin $\mathrm{E}$, and $\beta$-carotene also function to protect cells from the damaging effects of ROS. Despite a wide range of mechanisms to limit $\mathrm{O}_{2}^{-}$ production, over long periods of time ambient $\mathrm{O}_{2}$ levels of $21 \%$ still damage DNA, protein, and lipids. To deal with this molecular damage, inducible repair mechanisms protect the cell from increased ROS production. As noted earlier, however, in many instances the induction of these defenses actually requires oxidative modification of specific cell signaling proteins in order to initiate the protective response.

In short, the mechanisms that limit the amount of $\mathrm{H}_{2} \mathrm{O}_{2}$ and other ROS within the cell must work in a coordinated manner with redox-regulated signaling systems. Peroxiredoxins, catalase, and glutathione peroxidase are all capable of eliminating $\mathrm{H}_{2} \mathrm{O}_{2}$ efficiently [25,26], but exactly how these many mechanisms are coordinated is not fully understood - although a deeper understanding of the functions of specific ROS detoxification enzymes and their interactions with classical phosphorylation-based signal transduction systems is slowly emerging.

\section{Intracellular signaling mechanisms from oxygen and reactive oxygen species (hydrogen peroxide)}

Recent work has indicated that $\mathrm{H}_{2} \mathrm{O}_{2}$ is important as a signaling molecule, despite the molecule's short biological half-life, even though many questions remain unanswered about how it functions. The major unresolved issues include how $\mathrm{H}_{2} \mathrm{O}_{2}$ gradients or channels are formed and maintained in cells and organs in order to regulate protein function. $\mathrm{H}_{2} \mathrm{O}_{2}$ is also generated at the plasma membrane - for instance, by the dismutation of superoxide generated by the NADPH oxidases - where it has important roles in cell proliferation and other vital processes. Because $\mathrm{H}_{2} \mathrm{O}_{2}$ readily crosses membranes, some investigators have suggested that erythrocytes, which are rich in catalase, are cell-protective by functioning as a sink for extracellular $\mathrm{H}_{2} \mathrm{O}_{2}$ [27].

Because ROS-induced intracellular signaling is complex; investigators have used primary and transformed cell lines that can be easily manipulated to investigate $\mathrm{H}_{2} \mathrm{O}_{2}$ 's contribution to specific physiological functions. The amount of $\mathrm{H}_{2} \mathrm{O}_{2}$ required to function as a signaling molecule in various cell lines is an area of uncertainty, 
but it is generally very low. Low levels of $\mathrm{H}_{2} \mathrm{O}_{2}$ generated by the activation of many cell surface receptors, including transforming growth factor- $1 \beta$, TNF $\alpha$, granulocytemacrophage colony-stimulating factor, platelet-derived growth factor, and G-protein-coupled receptors, contribute to redox regulation and signal transduction [28-30]. Intracellular $\mathrm{H}_{2} \mathrm{O}_{2}$ targets specific proteins and changes their activation states. Many proteins that contain a deprotonated cysteine residue may be redox regulated and susceptible to oxidation by $\mathrm{H}_{2} \mathrm{O}_{2}$; most cysteine residues of many cytosolic proteins, however, are protonated due the low $\mathrm{pH}$ in the cytosol and therefore do not react with $\mathrm{H}_{2} \mathrm{O}_{2}[31,32]$. This effect may, however confer some specificity, and some proteins are directly redox regulated, such as ion channels, p53, and aconitase, either by the thiol mechanism or by changes in the oxidation-reduction state of iron or other transition metals [33]. Exposure to ROS leads to reversible oxidation of thiol groups of key cysteine residues in many downstream proteins, including transcriptional regulators, kinases, Rho and RAS GTPases, phosphatases, structural proteins, metabolic enzymes, and SUMO ligases.

\section{Kinases and phosphatases}

Kinases phosphorylate downstream proteins in active intracellular signal transduction cascades, usually after the stimulation of a receptor. Kinases may be activated or inhibited by phosphorylation, and several are known to be redox regulated, including prosurvival and proapoptotic kinases. For instance, $\mathrm{H}_{2} \mathrm{O}_{2}$ indirectly activates the prosurvival kinase Akt/PKB [34]. Akt appears to be necessary for host protection against multiorgan dysfunction from sepsis. Another kinase - apoptosissignaling kinase-1, a member of the mitogen-activated protein kinase kinase kinase family - activates the p38 and the JNK pathways by directly phosphorylating and activating SEK1 (MKK4)/MKK7) and MKK3/MKK6 $[35,36]$. Apoptosis-signaling kinase- 1 is activated in response to cytotoxic stress and under the presence of $\mathrm{H}_{2} \mathrm{O}_{2}$ induced by TNF $\alpha$ in HEK293 cells $[37,38]$. This kinase is also likely to play a role during sepsis, but how $\mathrm{H}_{2} \mathrm{O}_{2}$ manages to stimulate one kinase that is prosurvival versus one that results in cell death is an area of active investigation. Although understanding the nature of redox-based control of kinase activity is in its early stages and how these controls are affected during times of severe multisystem stress such as sepsis or trauma is just emerging, it is clear that excessive and nonspecific production of $\mathrm{H}_{2} \mathrm{O}_{2}$ during periods of oxidative stress interferes with specificity of redox regulation. Not only are some kinases redox regulated, but their dephosphorylating protein counterparts (phosphatases) may become inactivated in response to increased intracellular $\mathrm{H}_{2} \mathrm{O}_{2}$. Phosphatases often de-activate specific phosphoproteins that have been acted on by a kinase. For instance, protein tyrosine phosphatase-1B becomes inactivated in A431 human epidermoid carcinoma cells in response to epidermal growth factor-induced $\mathrm{H}_{2} \mathrm{O}_{2}$ production [39]. Insulin-induced $\mathrm{H}_{2} \mathrm{O}_{2}$ production also inactivates protein tyrosine phosphatase-1B [40]. Plateletderived growth factor has been shown to induce oxidation from intracellular $\mathrm{H}_{2} \mathrm{O}_{2}$ and to inhibit the $\mathrm{SH} 2$ domaincontaining protein tyrosine phosphatase SHP-2 in Rat-1 cells [41]. Phosphatase and tensin homolog is also regulated by $\mathrm{H}_{2} \mathrm{O}_{2}[42,43]$. As a general rule, phosphatase inactivation leads to unopposed activity of the reciprocal kinase; for example, phosphoinositide 3-kinase that activates Akt/PKB, a ubiquitous prosurvival kinase. The functional requirements for these proteins during times of critical illness are an area of active investigation.

\section{Transcription factors}

Not only does $\mathrm{H}_{2} \mathrm{O}_{2}$ regulate certain intracellular kinase and phosphatase pathways, it also interacts with specific redox-responsive nuclear transcription factors, coactivators, and repressors. Transcription factors typically become activated in response to signaling cascades activated both by membrane-bound receptors and by intracellular mechanisms. Transcriptional activation of a broad range of gene families are involved in cell survival, cell proliferation, antioxidant defense upregulation, DNA repair mechanisms, control of protein synthesis, and regulation of mitochondrial biogenesis. Among the transcription factors known to be activated in a redoxdependent manner are $\mathrm{Sp} 1$, the glucocorticoid receptor, Egr1, p53, NF-kB, NF-E2-related factor 2 (Nfe2l2 or Nrf2), hypoxia inducible factor- $1 \alpha$, and nuclear respiratory factor-1. Hypoxia inducible factor- $1 \alpha$ is a redoxsensitive transcription factor that provides an emergency survival response during severe hypoxic and inflammatory states. Several excellent reviews discuss the importance of these transcription factors and their downstream target genes $[44,45]$. NF- $\mathrm{kB}$ activation and Nrf2 (Nfe2l2) activation are also of particular importance in diseases that affect critically ill patients.

$\mathrm{NF}-\mathrm{kB}$ is bound in the cytoplasm to IкB in its inactive state [46]. Stimuli that activate NF- $k B$ induce the proteosomal degradation of IкB, allowing NF- $\kappa B$ to translocate to the nucleus and bind to $\mathrm{KB}$ motifs in the promoter region of many genes, including TNF $\alpha$ and inducible nitric oxide synthase (NOS2). $\mathrm{H}_{2} \mathrm{O}_{2}$ clearly modulates the function of NF-kB; however, whether its effects are inhibitory or activating appear to be cell-type specific [47]. $\mathrm{H}_{2} \mathrm{O}_{2}$ has been reported to increase the nuclear translocation of NF- $\mathrm{KB}[48,49]$, but other studies have shown the opposite effect [50]. Although NF-kB regulation by ROS is of significant importance during inflammatory states, recent work on other redox-regulated 


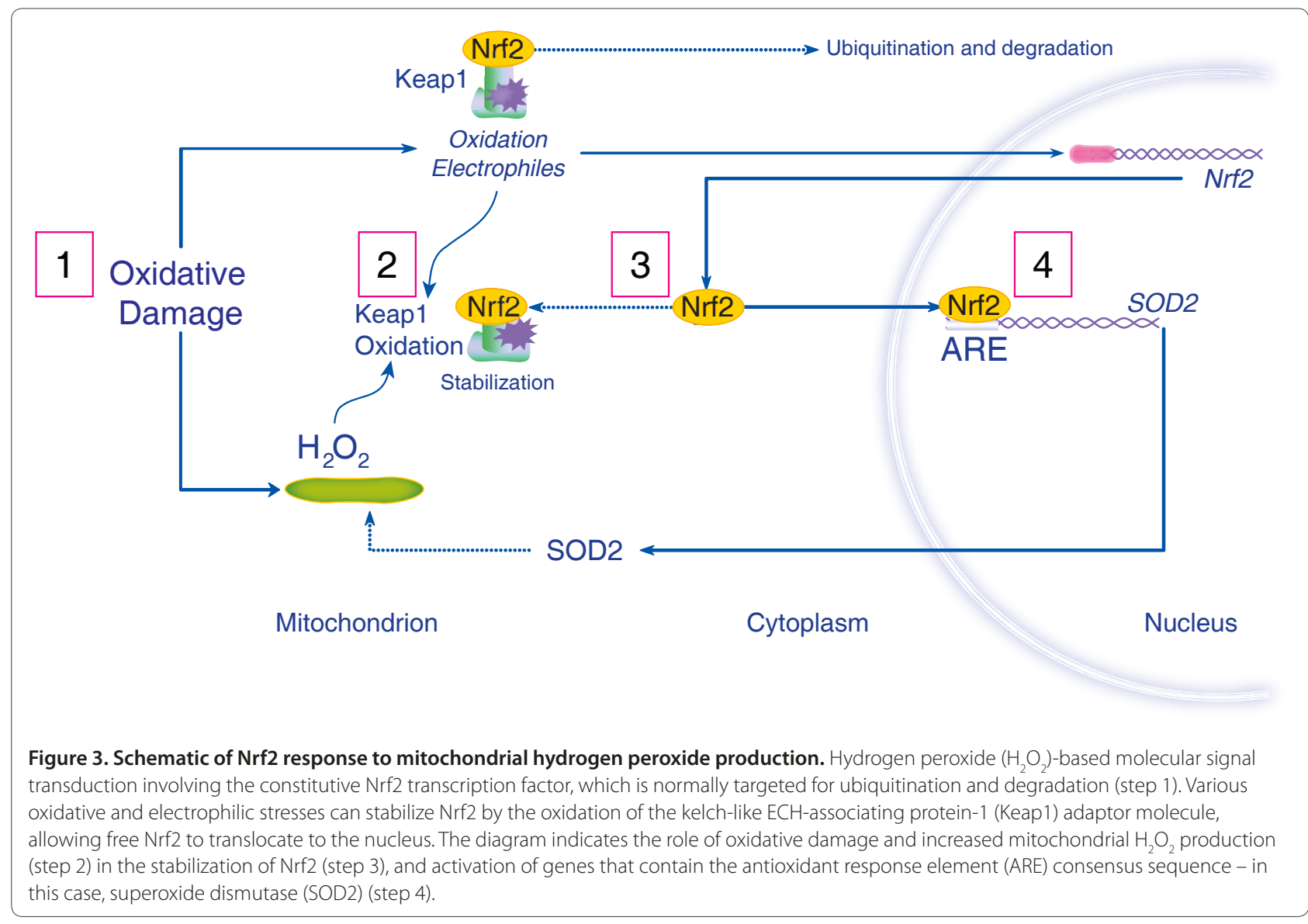

transcription factors such as $\mathrm{Nrf2}$ suggests that $\mathrm{H}_{2} \mathrm{O}_{2}$ has pluripotent effects.

Nrf2-dependent genes are critical for the maintenance of cellular redox homeostasis. This transcription factor is constitutively expressed in the cytoplasm and is regulated by ubiquitinylation under the dynamic control of kelchlike ECH-associating protein-1 $[44,51,52]$. In response to oxidative or electrophilic stress, kelch-like ECH-associating protein-1 is oxidized by $\mathrm{H}_{2} \mathrm{O}_{2}$. This event interferes with Nrf2 ubiquitinylation and its disposal by the proteasome, which allows Nrf2 to accumulate in the nucleus. Nuclear Nrf2 binds to the promoters of genes containing the antioxidant response element consensus sequence [53]. These genes include hepatic drugmetabolizing enzymes (cytochrome P450 isoforms) and many inducible antioxidant enzymes such as glutathione peroxidase, thioredoxin reductase, and peroxyredoxin-1. Nrf2 also induces HO-1, NAD(P)H quinone reductase-1, and $\gamma$-glutamyl cysteine ligase, which help regulate the intracellular redox state [54-57]. A simple schematic of Nrf2 response to mitochondrial $\mathrm{H}_{2} \mathrm{O}_{2}$ production is provided in Figure 3. Recent work suggests that Nrf2 transcriptional control plays a significant role in diseases associated with inflammatory stress $[58,59]$.

\section{Oxidative stress and disease}

In the healthy body, the ROS production and clearance rates are well balanced. Exogenous sources of oxidants and certain disease states can shift this balance by increasing the amount of ROS produced without adequate detoxification. For example, unchecked oxidative stress contributes to the pathogenesis of diabetes and its complications [60-62]. Neurodegenerative diseases, cancer, and aging are all associated with increased rates of ROS generation. Diseases in which acute or chronic inflammation is a significant component lead to excess extracellular ROS production that may tip the oxidantantioxidant balance towards acute and/or progressive organ damage, and nonspecific ROS production interferes with the normal signals generated by ROS. On the other hand, exuberant ROS production in phagocytic cells is critical for protection against microorganisms. The neutrophil kills bacteria through the induction of NADPH oxidase, which produces a burst of superoxide (oxidative burst). Recent work has also suggested that an $\mathrm{H}_{2} \mathrm{O}_{2}$ gradient is necessary for adequate wound healing (for example, in zebra fish), but the extent to which such gradients are necessary for mammalian wound healing is still being explored [63]. 
Oxidative repair (cell protection and proliferation): adaptation, conditioning, and hormesis

As mentioned earlier, not all oxidative stress is detrimental to cell survival; in fact, optimal health may require a certain amount of oxidative stress. The best example is arguably exercise, which induces ROS production followed by the coordinated upregulation of specific antioxidant enzymes, such as SOD2. It has been known for years that exercise induces ROS production beyond basal levels, although the exact rates, species, and quantities are unknown. Moreover, skeletal muscle ROS production during exercise affects organs other than the muscles, including the liver, by unknown but probably indirect mechanisms [64].

The idea that exposure to a small dose of a dangerous substance can induce a favorable biological response, long known as hormesis, has been applied to the presumed positive effects of $\mathrm{H}_{2} \mathrm{O}_{2}$ generated by exercise. Increased skeletal muscle contractile activity has been shown to produce superoxide, nitric oxide, hydrogen peroxide, hydroxyl radical, and peroxynitrite [65-69]. It was once believed that skeletal muscle mitochondria were the sole source of intracellular ROS during exercise $[70,71]$; however, other sources may derive from the sarcoplasmic reticulum, plasma membrane, or transverse tubules [72,73]. The stresses of muscle contraction during exercise that generates ROS are followed by the upregulation of catalase, protective protein thiols and the SODs [74]. $\mathrm{H}_{2} \mathrm{O}_{2}$ diffusing across membranes may result in protein/lipid oxidation of nearby cells during exercise [75], but the upregulation of the antioxidant enzymes as well as the redox regulation of mitochondrial biogenesis is probably responsible for many of the benefits seen with exercise training [76-78]. Indeed, the administration of large doses of low-molecular-weight antioxidants before exercise interferes with mitochondrial biogenesis in human subjects [79].

These and similar observations in other model systems offer an explanation for why blanket antioxidant supplementation is not the therapeutic panacea that was once hoped. A better understanding of how these molecular pathways are regulated will hopefully lead to new targets to induce intracellular protection and repair pathways during relevant critical disease states.

\section{Conclusions}

Oxygen is fundamental to the aerobic processes of eukaryotic life. Oxygen is consumed within the mitochondria to produce ATP, which is hydrolyzed to ADP to provide energy for all intracellular homeostatic and work functions. Because of oxygen's high chemical reactivity, however, advanced life-forms have had to evolve effective mechanisms to limit the biologically-damaging effects of $\mathrm{O}_{2}$ as well as the ability to utilize its intermediates to support cell signaling and damage control during health and disease. In particular, $\mathrm{H}_{2} \mathrm{O}_{2}$ has emerged as an important signaling molecule involved in the induction of the antioxidant defenses, cell repair mechanisms, and cell proliferation. Understanding how $\mathrm{H}_{2} \mathrm{O}_{2}$ and other ROS are produced, contained, and targeted will open up new avenues of understanding and should lead to novel interventional antioxidant strategies for use in health and disease.

\section{Abbreviations}

$\mathrm{HO}$, heme oxygenase; $\mathrm{H}_{2} \mathrm{O}_{2}$, hydrogen peroxide; $\mathrm{NF}$, nuclear factor; $\mathrm{O}_{2}$, oxygen; $\mathrm{O}_{2}^{-}$, superoxide anion; redox, oxidation-reduction; $\mathrm{ROS}$, reactive oxygen species; SOD, superoxide dismutase.

Competing interests

The authors declare that they have no competing interests.

\section{Author details}

'Department of Anesthesiology, Duke University School of Medicine, Box 3094, Durham, NC 27710, USA. ²Durham Veterans Affairs Medical Center, Duke University School of Medicine, 508 Fulton Street, Durham, NC 27705, USA 'Department of Medicine, Duke University School of Medicine, 200 Trent Drive, Durham, NC 27710, USA.

Published: 11 October 2010

\section{References}

1. Crapo JD: Morphologic changes in pulmonary oxygen toxicity. Annu Rev Physiol 1986, 48:721-731.

2. Rolfe DS, GC Brown: Cellular energy utilization and molecular origin of standard metabolic rate in mammals. Physio Reviews 1997, 77:731-758.

3. Babcock GT: How oxygen is activated and reduced in respiration. Proc Natl Acad Sci US A 1999, 96:12971-12973.

4. Sibson NR, Dhankhar A, Mason GF, Rothman DL, Behar KL, Shulman RG: Stoichiometric coupling of brain glucose metabolism and glutamatergic neuronal activity. Proc Natl Acad Sci US A 1998, 95:316-321.

5. Stanley WC, Recchia FA, Lopaschuk GD: Myocardial substrate metabolism in the normal and failing heart. Physiol Rev 2005, 85:1093-1129.

6. Siems WG, Sommerburg O, Grune T: Erythrocyte free radical and energy metabolism. Clin Nephrol 2000, 53(1 Suppl):S9-S17.

7. Auten RL, Davis JM: Oxygen toxicity and reactive oxygen species: the devil is in the details. Pediatr Res 2009, 66:121-127.

8. Miller G, Shulaev V, Mittler R: Reactive oxygen signaling and abiotic stress. Physiol Plant 2008, 133:481-489.

9. Imlay JA: Pathways of oxidative damage. Annu Rev Microbio/ 2003, 57:395-418.

10. Circu ML, AwTY: Reactive oxygen species, cellular redox systems and apoptosis. Free Radic Biol Med 2010, 48:749-762.

11. Aon MA, Cortassa S, O'Rourke B: Redox-optimized ROS balance: a unifying hypothesis. Biochim Biophys Acta 2010, 1797:865-877.

12. Balaban RS, Nemoto S, Finkel T: Mitochondria, oxidants, and aging. Cell 2005, 120:483-495

13. Barja G: Mitochondrial free radical production and aging in mammals and birds. Ann N Y Acad Sci 1998, 854:224-238.

14. Taylor DE, Ghio AJ, Piantadosi CA: Reactive oxygen species produced by liver mitochondria of rats in sepsis. Arch Biochem Biophys 1995, 316:70-76.

15. Fridovich I: Superoxide radical and superoxide dismutases. Annu Rev Biochem 1995, 64:97-112.

16. Hjalmarsson K, Marklund SL, Engstrom A, Edlund T: Isolation and sequence of complementary DNA encoding human extracellular superoxide dismutase. Proc Natl Acad Sci U S A 1987, 84:6340-6344

17. Lebovitz RM, Zhang H, Vogel H, Cartwright J Jr, Dionne L, Lu N, Huang S, Matzuk MM: Neurodegeneration, myocardial injury, and perinatal death in mitochondrial superoxide dismutase-deficient mice. Proc Natl Acad Sci USA 1996, 93:9782-9787

18. Fahimi HD: Cytochemical localization of peroxidatic activity of catalase in rat hepatic microbodies (peroxisomes). J Cell Biol 1969, 43:275-288.

19. Herzog V, Fahimi HD: A new sensitive colorimetric assay for peroxidase using 3,3'-diaminobenzidine as hydrogen donor. Anal Biochem 1973, 
55:554-562

20. Brigelius-Flohe R: Tissue-specific functions of individual glutathione peroxidases. Free Radic Biol Med 1999, 27:951-965

21. Fredenburgh LE, Perrella MA, Mitsialis SA: The role of heme oxygenase-1 in pulmonary disease. Am J Respir Cell Mol Biol 2007, 36:158-165.

22. Jancso G, Cserepes B, Gasz B, Benko L, Borsiczky B, Ferenc A, Kurthy M, Racz B, Lantos J, Gal J, Arato E, Sinayc L, Weber G, Roth E: Expression and protective role of heme oxygenase-1 in delayed myocardial preconditioning. Ann NY Acad Sci 2007, 1095:251-261.

23. Akamatsu Y, Haga M, Tyagi S, Yamashita K, Graca-Souza AV, Ollinger R, Czismadia E, May GA, Ifedigbo E, Otterbein LE, Bach FH, Soares MP: Heme oxygenase-1-derived carbon monoxide protects hearts from transplant associated ischemia reperfusion injury. FASEB J 2004, 18:771-772.

24. Piantadosi CA, Carraway MS, Babiker A, Suliman HB: Heme oxygenase-1 regulates cardiac mitochondrial biogenesis via Nrf2-mediated transcriptional control of nuclear respiratory factor-1. Circ Res 2008 , 103:1232-1240.

25. Rhee SG, Kang SW, Chang TS, Jeong W, Kim K: Peroxiredoxin, a novel family of peroxidases. IUBMB Life 2001, 52:35-41.

26. Kang SW, Chae HZ, Seo MS, Kim K, Baines IC, Rhee SG: Mammalian peroxiredoxin isoforms can reduce hydrogen peroxide generated in response to growth factors and tumor necrosis factor-alpha. J Bio/ Chem 1998, 273:6297-6302.

27. Winterbourn CC, Stern A: Human red cells scavenge extracellular hydrogen peroxide and inhibit formation of hypochlorous acid and hydroxyl radical. J Clin Invest 1987, 80:1486-1491.

28. Rhee SG, Kang SW, Jeong W, Chang TS, Yang KS, Woo HA: Intracellular messenger function of hydrogen peroxide and its regulation by peroxiredoxins. Curr Opin Cell Biol 2005, 17:183-189.

29. Sundaresan M, Yu ZX, Ferrans VJ, Irani K, Finkel T: Requirement for generation of $\mathrm{H} 2 \mathrm{O} 2$ for platelet-derived growth factor signal transduction. Science 1995, 270:296-299.

30. DeYulia GJ Jr, Carcamo JM, Borquez-Ojeda O, Shelton CC, Golde DW: Hydrogen peroxide generated extracellularly by receptor-ligand interaction facilitates cell signaling. Proc Natl Acad Sci U S A 2005, 102:5044-5049.

31. Bulaj G, Kortemme T, Goldenberg DP: Ionization-reactivity relationships for cysteine thiols in polypeptides. Biochemistry 1998, 37:8965-8972.

32. Sevier CS, Kaiser CA: Formation and transfer of disulphide bonds in living cells. Nat Rev Mol Cell Biol 2002, 3:836-847.

33. Matalon S, Hardiman KM, Jain L, Eaton DC, Kotlikoff M, Eu JP, Sun J, Meissner $G$, Stamler JS: Regulation of ion channel structure and function by reactive oxygen-nitrogen species. Am J Physiol Lung Cell Mol Physiol 2003, 285:L1184-L1189.

34. Ushio-Fukai M, Alexander RW, Akers M, Yin Q, Fujio Y, Walsh K, Griendling KK: Reactive oxygen species mediate the activation of Akt/protein kinase B by angiotensin II in vascular smooth muscle cells. J Biol Chem 1999, 274:22699-22704

35. Wang XS, Diener K, Jannuzzi D, Trollinger D, Tan TH, Lichenstein H, Zukowski $M$, Yao Z: Molecular cloning and characterization of a novel protein kinase with a catalytic domain homologous to mitogen-activated protein kinase kinase kinase. J Biol Chem 1996, 271:31607-31611.

36. Ichijo H, Nishida E, Irie K, ten Dijke P, Saitoh M, Moriguchi T, Takagi M, Matsumoto K, Miyazono K, Gotoh Y: Induction of apoptosis by ASK1, a mammalian MAPKKK that activates SAPK/JNK and p38 signaling pathways. Science 1997, 275:90-94.

37. Saitoh M, Nishitoh H, Fujii M, Takeda K, Tobiume K, Sawada Y, Kawabata M, Miyazono K, Ichijo H: Mammalian thioredoxin is a direct inhibitor of apoptosis signal-regulating kinase (ASK) 1. EMBO J 1998, 17:2596-2606.

38. Gotoh Y, Cooper JA: Reactive oxygen species- and dimerization-induced activation of apoptosis signal-regulating kinase 1 in tumor necrosis factoralpha signal transduction. J Bio/ Chem 1998, 273:17477-17482.

39. Lee SR, Kwon KS, Kim SR, Rhee SG: Reversible inactivation of proteintyrosine phosphatase 1B in A431 cells stimulated with epidermal growth factor. J Biol Chem 1998, 273:15366-15372.

40. Mahadev K, Zilbering A, Zhu L, Goldstein BJ: Insulin-stimulated hydrogen peroxide reversibly inhibits protein-tyrosine phosphatase $1 \mathrm{~b}$ in vivo and enhances the early insulin action cascade. J Biol Chem 2001, 276:21938-21942.

41. Meng TC, Fukada T, Tonks NK: Reversible oxidation and inactivation of protein tyrosine phosphatases in vivo. Mo/ Cell 2002, 9:387-399.
42. Lee $\mathrm{K}$, Esselman WJ: Inhibition of PTPs by $\mathrm{H}_{2} \mathrm{O}_{2}$ regulates the activation of distinct MAPK pathways. Free Radic Biol Med 2002, 33:1121-1132.

43. Cho SH, Lee $\mathrm{CH}, \mathrm{Ahn}$ Y, Kim H, Ahn CY, Yang KS, Lee SR: Redox regulation of PTEN and protein tyrosine phosphatases in $\mathrm{H}_{2} \mathrm{O}_{2}$ mediated cell signaling. FEBS Lett 2004, 560:7-13.

44. Nguyen T, Nioi P, Pickett CB: The Nrf2-antioxidant response element signaling pathway and its activation by oxidative stress. J Bio/ Chem 2009, 284:13291-13295.

45. Groeger G, Quiney C, Cotter TG: Hydrogen peroxide as a cell-survival signaling molecule. Antioxid Redox Signal 2009, 11:2655-2671.

46. Baeuerle PA, Baltimore D: IкB: a specific inhibitor of the NF-кB transcription factor. Science 1988, 242:540-546.

47. Gloire G, Legrand-Poels S, Piette J: NF-KB activation by reactive oxygen species: fifteen years later. Biochem Pharmacol 2006, 72:1493-1505.

48. Dalton TP, Shertzer HG, Puga A: Regulation of gene expression by reactive oxygen. Annu Rev Pharmacol Toxicol 1999, 39:67-101.

49. Barchowsky A, Munro SR, Morana SJ, Vincenti MP, Treadwell M: Oxidantsensitive and phosphorylation-dependent activation of NF-KB and AP-1 in endothelial cells. Am J Physiol 1995, 269(6 Pt 1):L829-L836.

50. Hayakawa M, Miyashita H, Sakamoto I, Kitagawa M, Tanaka H, Yasuda H, Karin $M$, Kikugawa K: Evidence that reactive oxygen species do not mediate NF-kB activation. EMBO J 2003, 22:3356-3366.

51. Itoh K, Wakabayashi N, Katoh Y, Ishii T, Igarashi K, Engel JD, Yamamoto M: Keap1 represses nuclear activation of antioxidant responsive elements by Nrf2 through binding to the amino-terminal Neh2 domain. Genes Dev 1999, 13:76-86.

52. Itoh K, Tong Kl, Yamamoto M: Molecular mechanism activating Nrf2-Keap1 pathway in regulation of adaptive response to electrophiles. Free Radic Biol Med 2004, 36:1208-1213.

53. Itoh K, Chiba T, Takahashi S, Ishii T, Igarashi K, Katoh Y, Oyake T, Hayashi N, Satoh K, Hatayama I, Yamamoto M, Nabeshima Y: An Nrf2/small Maf heterodimer mediates the induction of phase II detoxifying enzyme genes through antioxidant response elements. Biochem Biophys Res Commun 1997, 236:313-322.

54. Prestera T, Talalay P: Electrophile and antioxidant regulation of enzymes that detoxify carcinogens. Proc Natl Acad Sci U S A 1995, 92:8965-8969.

55. Mulcahy RT, Wartman MA, Bailey HH, Gipp JJ: Constitutive and $\beta$-naphthoflavone-induced expression of the human $\gamma$-glutamylcysteine synthetase heavy subunit gene is regulated by a distal antioxidant response element/TRE sequence. J Bio/ Chem 1997, 272:7445-7454.

56. Itoh K, Ishii T, Wakabayashi N, Yamamoto M: Regulatory mechanisms of cellular response to oxidative stress. Free Radic Res 1999, 31:319-324

57. Itoh K, Mochizuki M, Ishii Y, Ishii T, Shibata T, Kawamoto Y, Kelly V, Sekizawa K, Uchida K, Yamamoto M: Transcription factor Nrf2 regulates inflammation by mediating the effect of 15 -deoxy- $\Delta(12,14)$-prostaglandin $\mathrm{J}_{2}$. Mol Cell Biol 2004, 24:36-45

58. Jiang T, Huang Z, Lin Y, Zhang Z, Fang D, Zhang DD: The protective role of Nrf2 in STZ-induced diabetic nephropathy. Diabetes 2010, in press.

59. Cho HY, Reddy SP, Kleeberger SR: Nrf2 defends the lung from oxidative stress. Antioxid Redox Signal 2006, 8:76-87.

60. Giugliano D, Ceriello A, Paolisso G: Oxidative stress and diabetic vascular complications. Diabetes Care 1996, 19:257-267.

61. Ceriello A: New insights on oxidative stress and diabetic complications may lead to a 'causal' antioxidant therapy. Diabetes Care 2003, 26:1589-1596.

62. Wiernsperger NF: Oxidative stress as a therapeutic target in diabetes: revisiting the controversy. Diabetes Metab 2003, 29:579-585

63. Niethammer P, Grabher C, Look AT, Mitchison TJ: A tissue-scale gradient of hydrogen peroxide mediates rapid wound detection in zebrafish. Nature 2009, 459:996-999.

64. Close GL, Kayani AC, Ashton T, McArdle A, Jackson MJ: Release of superoxide from skeletal muscle of adult and old mice: an experimental test of the reductive hotspot hypothesis. Aging Cell 2007, 6:189-195.

65. Pattwell DM, McArdle A, Morgan JE, Patridge TA, Jackson MJ: Release of reactive oxygen and nitrogen species from contracting skeletal muscle cells. Free Radic Biol Med 2004, 37:1064-1072.

66. McArdle A, van der Meulen J, Close GL, Pattwell D, Van Remmen H, Huang TT, Richardson AG, Epstein CJ, Faulkner JA, Jackson MJ: Role of mitochondria superoxide dismutase in contraction-induced generation of reactive oxygen species in skeletal muscle extracellular space. Am J Physio/ Cell Physiol 2004, 286:C1152-C1158. 
67. Vasilaki A, Mansouri A Remmen H, van der Meulen JH, Larkin L, Richardson AG, McArdle A, Faulkner JA, Jackson MJ: Free radical generation by skeletal muscle of adult and old mice: effect of contractile activity. Aging Cell 2006 5:109-117.

68. Pye D, Palomero J, Kabayo T, Jackson MJ: Real-time measurement of nitric oxide in single mature mouse skeletal muscle fibres during contractions. $J$ Physiol 2007, 581:309-318.

69. Close GL, Ashton T, McArdle A, Jackson MJ: Microdialysis studies of extracellular reactive oxygen species in skeletal muscle: factors influencing the reduction of cytochrome $\mathrm{c}$ and hydroxylation of salicylate. Free Radic Biol Med 2005, 39:1460-1467.

70. Davies KJ, Quintanilha AT, Brooks GA, Packer L: Free radicals and tissue damage produced by exercise. Biochem Biophys Res Commun 1982, 107:1198-1205

71. Koren A, Sauber C, Sentjurc M, Schara M: Free radicals in tetanic activity of isolated skeletal muscle. Comp Biochem Physiol B 1983, 74:633-635.

72. Xia R, Webb JA, Gnall LL, Cutler K, Abramson JJ: Skeletal muscle sarcoplasmic reticulum contains a $\mathrm{NADH}$-dependent oxidase that generates superoxide. Am J Physiol Cell Physiol 2003, 285:C215-C221.

73. Javesghani D, Magder SA, Barreiro E, Quinn MT, Hussain SN: Molecular characterization of a superoxide-generating $\mathrm{NAD}(\mathrm{P}) \mathrm{H}$ oxidase in the ventilatory muscles. Am J Respir Crit Care Med 2002, 165:412-418.

74. McArdle A, Pattwell D, Vasilaki A, Griffiths RD, Jackson MJ: Contractile activity-induced oxidative stress: cellular origin and adaptive responses. Am J Physiol Cell Physiol 2001, 280:C621-C627.
75. Szczesniak L, Karolkiewicz J, Deskur E, Rychlewski T, Konys L, Stankiewicz K: The influence of exercise-induced oxidative stress on binding and degradation of ${ }^{125}$-insulin by the receptors on erythrocytes. J Physiol Pharmacol 1998, 49:421-432.

76. Geng T, Li P, Okutsu M, Yin X, Kwek J, Zhang M, Yan Z: PGC-1 a plays a functional role in exercise-induced mitochondrial biogenesis and angiogenesis but not fiber-type transformation in mouse skeletal muscle. Am J Physiol Cell Physiol 2010, in press.

77. Kang C, O'Moore KM, Dickman JR, Ji LL: Exercise activation of muscle peroxisome proliferator-activated receptor-gamma coactivator-1alpha signaling is redox sensitive. Free Radic Bio/ Med 2009, 47:1394-1400.

78. Ljubicic V, Joseph AM, Saleem A, Uguccioni G, Collu-Marchese M, Lai RY, Nguyen LM, Hood DA: Transcriptional and post-transcriptional regulation of mitochondrial biogenesis in skeletal muscle: effects of exercise and aging. Biochim Biophys Acta 2010, in press.

79. Ristow M, Zarse K, Oberbach A, Kloting N, Birringer M, Kiehntopf M, Stumvoll M, Kahn CR, Bluher M: Antioxidants prevent health-promoting effects of physical exercise in humans. Proc Natl Acad Sci U S A 2009, 106:8665-8670.

doi:10.1186/cc9185

Cite this article as: Bartz RR, Piantadosi CA: Oxygen as a signaling molecule. Critical Care 2010, 14:234 